\title{
Changes in starch physical characteristics following digestion of foods in the human small intestine
}

\author{
Zhongkai Zhou ${ }^{1}$, David L. Topping ${ }^{1}$, Matthew K. Morell ${ }^{2}$ and Anthony R. Bird ${ }^{1}$ * \\ ${ }^{1}$ Food Futures National Research Flagship, CSIRO Food and Nutritional Sciences, Kintore Avenue, Adelaide 5000, Australia \\ ${ }^{2}$ Food Futures National Research Flagship, CSIRO Plant Industry, Canberra ACT 2601, Australia
}

(Received 5 June 2009 - Revised 11 February 2010 - Accepted 12 February 2010 - First published online 23 April 2010)

Factors controlling the concentration of resistant starch (RS) in foods are of considerable interest on account of the potential for this type of fibre to deliver health benefits to consumers. The present study was aimed at establishing changes in starch granule morphology as a result of human smallintestinal digestion. Volunteers with ileostomy consumed six selected foods: breakfast cereal (muesli), white bread, oven-baked French fries, canned mixed beans and a custard containing either a low-amylose maize starch (LAMS) or a high-amylose maize starch (HAMS). Analysis showed that digesta total RS (as a fraction of ingested starch) was: muesli, $8.9 \%$; bread, $4.8 \%$; fries, $4.2 \%$; bean mix, 35.9\%; LAMS custard, 4.0\%; HAMS custard, 29.1\%. Chromatographic analysis showed that undigested food contained three major starch fractions. These had average molecular weights (MW) of $43500 \mathrm{kDa}, 420 \mathrm{kDa}$ and $8.5 \mathrm{kDa}$ and were rich in amylopectin, higher-MW amylose and low-MW amylose, respectively. The low-MW amylose fraction became enriched preferentially in the stomal effluent while the medium-MW starch fraction showed the greatest loss. Fourier transform IR spectroscopy showed that absorbance at 1022 per $\mathrm{cm}$ decreased after digestion while the absorbance band at 1047 per $\mathrm{cm}$ became greater. Such changes have been suggested to indicate shifts from less ordered to more ordered granule structures. Further analysis of amylose composition by scanning iodine spectra indicated that the MW of amylose in ileal digesta was lower than that of undigested amylose. It appears that high-MW amylose is preferentially digested and that MW, rather than amylose content alone, is associated with resistance of starch to digestion in the upper gut of humans.

Resistant starch: Structure: Morphology: Ileal digesta: Human subjects

Controlling the rate and extent of small-intestinal digestion of starch has important implications for human health. Slowing the rate of amylolysis lowers the glycaemic response to foods and is of established benefit in improving blood glucose control $^{(1)}$. However, the extent of human small-intestinal starch digestion is emerging as an important potential contributor to lower risk of diseases such as colorectal cancer. Resistant starch (RS) is that fraction of starch (and the products of starch digestion) that escapes from the human small intestine into the large bowel of healthy individuals ${ }^{(2)}$. RS contributes to dietary fibre by virtue of its small-intestinal indigestibility and exerts its beneficial actions largely through the SCFA, especially butyrate, produced during its fermentation by the large-bowel microflora ${ }^{(3)}$.

The RS content of a food is subject to a number of influences, including processing, the physical accessibility of the starch granule architecture and the degree to which any gelatinised starch has been allowed to retrograde ${ }^{(4)}$. The molecular and structural properties of starches are also important primary determinants of their resistance to amylolysis. For example, high-amylose starches are generally slower to gelatinise on cooking and quicker to retrograde (and thus exhibit higher resistance to amylolysis) on subsequent cooling than conventional starches. Up to the present, attention has mostly been focused on the quantity of RS in a food, possibly because of an assumption that net SCFA production and the profile of the acids produced were the same for RS from different sources. However, there is some evidence that this is not the case and starches differ markedly in their capacity to produce different amounts and proportions of individual $\operatorname{SCFA}^{(5,6)}$. While RS in general favours butyrate production $^{(7)}$ it has been reported that the microflora of some individuals cannot metabolise some types of $\mathrm{RS}^{(8)}$, which raises the issue of identifying the factors that cause the resistance of starch to bacterial degradation.

Quantitative data on the relationship between dietary starches and structural characteristics of RS, specifically at the molecular level, are still very limited. In part this reflects the difficulty of accessing the human intestine to obtain starch post-digestion. The objective of the present study was to obtain information on the differences in starch morphology and molecular characteristics in a number of

Abbreviations: FTIR, Fourier transform IR spectroscopy; HAMS, high-amylose maize starch; HMW, high-molecular weight; LAMS, low-amylose maize starch;

LMW, low-molecular weight; MMW, medium-molecular weight; MW, molecular weight; RS, resistant starch; SE-HPLC, size exclusion HPLC

* Corresponding author: Dr Anthony R. Bird, fax +61 88303 8899, email tony.bird@csiro.au 
Table 1. Test foods used in feeding trials and ileal starch digestibility

(Mean values with their standard errors)

\begin{tabular}{|c|c|c|c|c|c|c|c|c|c|}
\hline \multirow[b]{2}{*}{ Test food } & \multirow{2}{*}{$\begin{array}{l}\text { Serving size } \\
\text { (g, as-is) }\end{array}$} & \multirow{2}{*}{$\begin{array}{l}\text { Moisture } \\
\text { content (\%) }\end{array}$} & \multirow{2}{*}{$\begin{array}{l}\text { Total food } \\
\text { consumed } \\
\text { (g, dry) }\end{array}$} & \multicolumn{2}{|c|}{$\begin{array}{c}\text { Total starch } \\
\text { ingested }(\mathrm{g}, \text { dry })^{\star}\end{array}$} & \multicolumn{2}{|c|}{$\begin{array}{l}\text { Starch collected in } \\
\text { digesta }(g, \text { dry) } \dagger\end{array}$} & \multicolumn{2}{|c|}{$\begin{array}{l}\text { Starch digest- } \\
\text { ibility }(\mathrm{g} / 100 \mathrm{~g} \\
\text { starch }) \ddagger\end{array}$} \\
\hline & & & & Mean & SEM & Mean & SEM & Mean & SEM \\
\hline \multicolumn{10}{|l|}{ Trial 1} \\
\hline Muesli§̧ & 90 & $7 \cdot 2$ & 83.5 & 41.4 & 0.1 & $3 \cdot 7$ & 0.6 & 91.1 & 1.3 \\
\hline White bread\| & 141 & $32 \cdot 8$ & 94.8 & $72 \cdot 8$ & 0.1 & 3.5 & 0.2 & $95 \cdot 2$ & 0.4 \\
\hline Potato fries (oven-baked) & 250 & $52 \cdot 0$ & $120 \cdot 0$ & 73.8 & 1.4 & $3 \cdot 1$ & 0.2 & $95 \cdot 8$ & 0.6 \\
\hline Mixed beans (canned)ף & 100 & 69.9 & $30 \cdot 1$ & $13 \cdot 2$ & 0.5 & 4.7 & 0.5 & $64 \cdot 1$ & 3.4 \\
\hline \multicolumn{10}{|l|}{ Trial 2} \\
\hline $\begin{array}{l}\text { Custard containing } \\
\text { conventional maize starch (LAMS) }\end{array}$ & 132 & 64.7 & $46 \cdot 6$ & $18 \cdot 6$ & 0.1 & 0.7 & 0.1 & $96 \cdot 0$ & 0.3 \\
\hline Custard containing HAMS & 132 & $65 \cdot 7$ & $45 \cdot 3$ & $19 \cdot 7$ & $0 \cdot 1$ & $5 \cdot 7$ & 0.3 & $70 \cdot 9$ & 2.5 \\
\hline
\end{tabular}

LAMS, low-amylose maize starch; HAMS, high-amylose maize starch.

* Values of triplicate determinations for each food.

$\dagger$ Eight observations.

$\ddagger$ Calculated as the difference in the amount of starch consumed and subsequently recovered in ileal digesta divided by the amount of the starch consumed.

$\S$ Commercial breakfast cereal containing multiple cereal grains and other sources of starch.

\| Refined white wheat bread; formulation contains a HAMS (Hi-maize $\left.{ }^{\circledR}\right)$.

$\uparrow$ Canned product containing four different varieties of beans. Beans were drained before consumption.

foods before and after digestion in vivo in order to provide greater insight into the molecular structure of digestible and resistant starches. This was achieved using volunteers with ileostomy - an accepted means of examining human small-intestinal digestion ${ }^{(9)}$.

\section{Materials and methods}

\section{Subjects}

Eight individuals (seven males, one female) contributed samples of ileostomy effluent for the present study. The volunteers were participating in two other studies investigating different aspects of starch digestion (AR Bird, DL Topping, $S$ Usher and D Davies, unpublished results ${ }^{(10)}$. They had undergone minimal small-bowel resection (apparently $<10 \mathrm{~cm}$ ) for inflammatory bowel disease or cancer and all had conventional and well-functioning permanent ileostomy and no known intestinal inflammation at the time of study. Three subjects had been ileostomised during the previous 3 years whereas the others had experienced surgery more than 20 years ago. Volunteers had a mean age of 58 (range 37-81) years and an average weight of $72(60-90) \mathrm{kg}$ and generally were in good health. The present study was conducted according to the guidelines laid down in the Declaration of Helsinki and all procedures involving human subjects were approved by the Australian Commonwealth Scientific and Research Organisation (CSIRO) Food and Nutritional Sciences Human Experimentation Ethics Committee. Written informed consent was obtained from all subjects before commencement.

\section{Test foods, study design and protocol}

Six different food products (four commercially processed foods: muesli, white bread, oven-baked potato fries and canned bean mix; two custards containing either conventional maize starch or high-amylose maize starch; HAMS) were chosen in the present study, as they are among the most common foods in Western diets. The foods were consumed in random order in the two trials (Table 1). In trial 1, locally available commercially processed foods were consumed after preparation as instructed by the manufacturer. The amounts consumed exceeded the recommended serving sizes to ensure an adequate level of starch in ileal digesta. For trial 2 , volunteers consumed milk-based chocolate custards (about $120 \mathrm{~g}$ ) containing $20 \mathrm{~g}$ of one of two commercially available low-amylose maize starch (LAMS) and HAMS (3401C and Hylon ${ }^{\circledR}$ VII, respectively; National Starch and Chemical Company, Seven Hills, NSW, Australia). In addition to these ingredients the custards also contained a small amount of honey for flavouring $(12 \mathrm{~g})$. The custards were made to industry standards in an experimental kitchen.

The study comprised a total of eight feeding periods of either two (trial 1) or three (trial 2) consecutive days' duration in which all volunteers consumed a low $(<60$ and $5 \mathrm{~g} / \mathrm{d}$, respectively) starch basal diet comprising mostly staple food items (for example, various red and white meats, dairy foods, eggs, fruits, fruit juices and non-starchy vegetables) consumed as three main meals and several snacks each day. All foods for the trial were supplied by CSIRO. Using Australian food composition databases, protein, fat and carbohydrate were calculated to provide about 27,37 and $35 \%$ of energy, respectively. Total dietary fibre intake was estimated to be $14 \mathrm{~g} / \mathrm{d}$. For some individuals the composition of the basal diet was varied slightly to meet individual preference and appetite. However, for each individual the same diet was eaten on each day of a given feeding period. Volunteers were asked to refrain from drinking alcoholic beverages during the feeding phases of the study. The weights of any uneaten foods were recorded. Meals were eaten at specified times and test foods (see Table 1) were consumed at breakfast on either $1 \mathrm{~d}$ (trial 1) or $2 \mathrm{~d}$ (trial 2) of the feeding periods. Each volunteer thereby served as his or her own control. 


\section{Ileal digesta collection and sampling}

All ileostomy effluent was collected at $2 \mathrm{~h}$ intervals during each feeding period. Collection was from 07.00 hours in both studies and finished at either 19.00 hours (trial 2) or 23.00 hours (trial 1) on each day. The final collection was made at 07.00 hours on the morning following the final full collection day of each feeding period. At each collection, the entire contents of each ileostomy bag were drained into sterile plastic pots, which were capped and immediately frozen to await analysis.

Ileostomy samples collected during each $24 \mathrm{~h}$ period were thawed, pooled and homogenised. Duplicate portions of digesta and each test food were taken immediately, lyophilised and analysed later for glucose and starch.

\section{Analytical procedures}

Starch and starch morphology. A sample $(30 \mathrm{ml})$ of aqueous ethanol (80:20, ethanol-water, v/v) was added to $80 \mathrm{mg}$ of freeze-dried food and digesta in separate $50 \mathrm{ml}$ polypropylene centrifuge tubes. The contents of each tube (capped) were mixed by hand shaking for $5 \mathrm{~min}$, and then centrifuged at $2095 \mathrm{~g}$ for $10 \mathrm{~min}$. The supernatant fraction was aspirated to waste and the pellet was re-suspended in $25 \mathrm{ml}$ acetone. The shaking and centrifuge procedures were repeated. The final pellet (in a $50 \mathrm{ml}$ tube) was air dried in a fume hood and sprinkled onto circular aluminium stubs containing double sticky tape. The stubs were coated with gold in a Hitachi 1B-3 ion coater. Starch granules and fragments were visualised using a scanning electron microscope (Autoscan Systems Pty Ltd, Brighton, Vic, Australia). The image of the selected area was recorded on a black and white highspeed photographic film with the help of an attached camera assembly. Each food and digesta sample was examined in triplicate.

Fourier transform IR spectroscopy. Fourier transform IR spectroscopy (FTIR) spectra were recorded on a spectrophotometer (Excalibur 3100; Varian Australia Pty Ltd, Melbourne, Vic, Australia) equipped with a cooled deuterated triglycine sulfate (DTGS) detector. The measurement was performed on a MIRacle ${ }^{\mathrm{TM}}$ attenuated total reflectance (ATR) crystal plate with Digital Readout High Pressure Clamp (Pike Technologies, Madison, WI, USA). Freeze-dried food products and digesta were directly loaded on the plate and scanned in the range of 3600-600 per $\mathrm{cm}$ at a resolution of 4 per $\mathrm{cm}$. Before recording, the spectra were transformed against an empty cell as background. Finally the spectra were deconvoluted using Resolutions Pro software (Varian Inc., Palo Alto, CA, USA). A half-bandwidth of 15 per $\mathrm{cm}$ and a $\mathrm{K}$ factor of 1.5 with triangular apodisation were applied. Absorbance values at 1047 and 1022 per cm were obtained from each spectrum and are considered indicative of more or less order in starch structures, respectively ${ }^{(11-13)}$.

Starch and resistant starch molecular size distribution. An $8 \mathrm{ml}$ sample of aqueous dimethylsulfoxide (90:10, dimethylsulfoxide-water, v/v) was added to either $20 \mathrm{mg}$ of freezedried food or $80 \mathrm{mg}$ of freeze-dried digesta in separate $25 \mathrm{ml}$ test-tubes. Each tube was capped and the mixture was allowed to stand at room temperature for $24 \mathrm{~h}$ with occasional stirring on a vortex mixer. The mixture was centrifuged at $2095 \mathrm{~g}$ for
10 min and the supernatant fraction was aspirated into a separate $25 \mathrm{ml}$ test-tube and the starch was precipitated by the addition of $18 \mathrm{ml}$ of $95 \%$ aqueous ethanol. The tubes were kept at $4^{\circ} \mathrm{C}$ overnight and then centrifuged (2095 $g$ for $15 \mathrm{~min})$. The starch precipitate was collected for subsequent analyses by size exclusion HPLC (SE-HPLC) and UV-visible spectrophotometry.

The starch precipitate (approximately $20 \mathrm{mg}$ ), prepared as described earlier, was redissolved in $0.5 \mathrm{ml}$ of $0.2 \mathrm{M}-\mathrm{NaOH}$ and mixed vigorously for approximately $10 \mathrm{~s}$. The solution was neutralised by the addition of sodium acetate buffer (0.5 ml; $0.05 \mathrm{M}, \mathrm{pH} 4.0)$ before adding ion-exchange resin (0.20 g, BioRad $\mathrm{AG}^{\circledR}$ 501-X8; Bio-Rad, Hercules, CA, USA) and incubating at $50^{\circ} \mathrm{C}$ for $1.5 \mathrm{~h}$ with occasional shaking. After centrifuging at $10000 \mathrm{rpm}$ for $10 \mathrm{~min}$ (Centrifuge 5415D; Eppendorf, Hamburg, Germany), the clear supernatant fractions were collected for SE-HPLC analysis. The HPLC system comprised a GBC pump (LC 1150; GBC Instruments, Dandenong, Vic, Australia) equipped with an Auto Sampler (LC1610; GBC Instruments) and Evaporative Light Scattering Detector (ELSD) (Alltech Associates, Deerfield, IL, USA). The Ultrahydrogel ${ }^{\mathrm{TM}}$ linear column, Ultrahydrogel ${ }^{\mathrm{TM}} 250$ column and guard column $(7.8 \mathrm{~mm} \times 300 \mathrm{~mm}$; Waters, Osaka, Japan) were used and maintained at $35^{\circ} \mathrm{C}$ during HPLC operation. Ammonium acetate buffer (0.05 M; pH 5.2) was used as the mobile phase at a flow rate of $0.8 \mathrm{ml} / \mathrm{min}$. A sample $(50 \mu \mathrm{l})$ of the supernatant fraction was used for injection. Conditions for ELSD operation were: tube temperature, $115^{\circ} \mathrm{C} ; \mathrm{N}_{2}$ gas flow rate, 2.0 litres/min; gain, 16; impactor, on. Dextran standards with molecular weights (MW) of 4900, 670, 150, 80, 25 and $5 \mathrm{kDa}$ were used for column calibrations.

Starch-iodine spectrum. The iodine-complexing spectrum of starch was used to examine the changes in the amylose compositions before and after the digestion. The clear supernatant fraction, prepared for HPLC analysis as described earlier, was also used for the study of the amylose-iodine spectrum by UV-visible spectrophotometry. A quantity of $25 \mu \mathrm{l}$ of $\mathrm{I}_{2}-\mathrm{KI}$ solution $\left(1.27 \mathrm{~g} \mathrm{I}_{2}+3 \mathrm{~g}\right.$ KI per litre) was added into $0.5 \mathrm{ml}$ of the starch solution. After dilution using distilled water, the absorbance was recorded at $1 \mathrm{~nm}$ intervals from 350 to 800 per $\mathrm{cm}$ using a Varian (Model Cary 1E; Varian, Inc., Palo Alto, CA, USA) scanning UVvisible spectrophotometer and spectral analyses performed in triplicate.

\section{Statistical analyses}

RS content of a given test food was calculated as the difference between ileal starch output for the test food and that of the control (i.e. low-starch) diet. RS values are expressed on either a food or total starch basis. Values are expressed as means with their standard errors of three replicates for test foods and digesta samples from eight individuals. Both trials were considered to be completely randomised designs and the experimental data were subjected to one-way ANOVA using Genstat 5 (version 4.1, 1998; VSN International, Hemel Hempstead, Bucks, UK). Differences among test foods were assessed using the least significant difference procedure. Effects were considered significant at $P<0 \cdot 05$. 


\section{Results}

The quantities of food and starch consumed by the volunteers are shown in Table 1. The apparent digestibility of the starches ranged from $64 \%$ for canned beans to $96 \%$ for custard containing LAMS (Table 1). The RS content (expressed as a percentage of ingested starch) was: for muesli, 8.9\%; for bread, $4.8 \%$; for fries, $4.2 \%$; for beans, $35.9 \%$; for LAMS custard, $4.0 \%$; for HAMS custard, $29.1 \%$, respectively. The starches were fractionated by SE-HPLC into high-MW (HMW), medium-MW (MMW) and low-MW (LMW) fractions (Fig. 1). The peak materials in these fractions were eluted at the same elution time as MW standards of approximately $43500 \mathrm{kDa}, \quad 420 \mathrm{kDa}$ and $8.5 \mathrm{kDa}$, respectively. HMW was assumed to be principally amylopectin, because its MW was reported to vary from $10^{7}$ to $10^{9} \mathrm{Da}^{(14,15)}$, whereas amylose has a relatively lower MW compared with amylopectin, ranging from $10^{5}$ to $10^{6} \mathrm{Da}$. Accordingly, MMW was considered to be mostly (but not exclusively) higher-MW amylose whereas LMW was considered to comprise mostly lower-MW amylose. Using a dual-column system, a previous study on the molecular structure of starches with different amylose contents by Shi et al. ${ }^{(16)}$ also suggested that starch molecules could be separated into these fractions: a HMW amylopectin fraction, a LMW amylose fraction, and an intermediate MW fraction which contains both linear and branched starch molecules.

Representative SE-HPLC chromatograms for starch in one product (muesli) before and after passage through the small intestine of one volunteer are presented in Fig. 1. A LMW
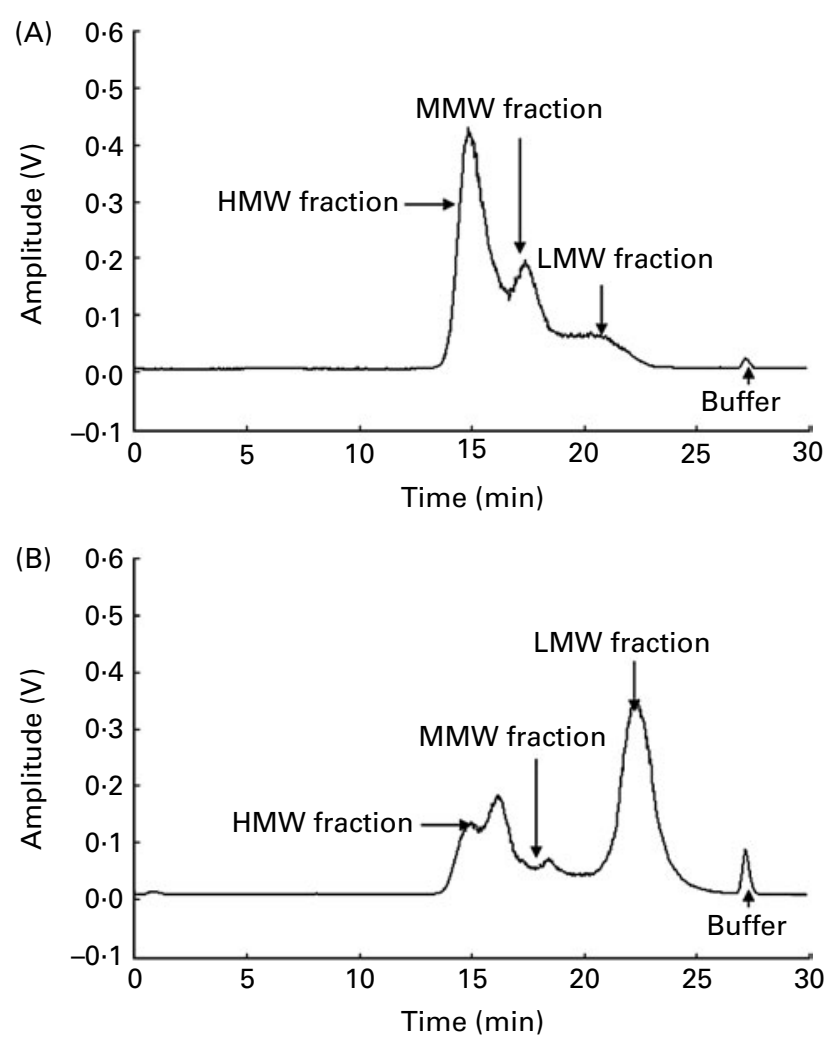

Fig. 1. Molecular profile of starch in (A) muesli and (B) its corresponding ileal digesta sample from one volunteer. HMW, high molecular weight; MMW, medium molecular weight; LMW, low molecular weight. fraction of approximately $4 \cdot 1 \mathrm{kDa}$ was found to predominate in starch that had escaped digestion. In a similar study using human ileostomates who had consumed a chick pea starch gel, chromatographic analysis of ileal effluent demonstrated that a fraction of lower MW with weight-average degree of polymerisation of 25 was found to be the major peak ${ }^{(17)}$. Canned beans and HAMS custard contained starches of lesser digestibility consisting mostly of LMW and MMW fractions and, consequently, relatively little HMW starch (accounting for just 9 and $16 \%$ of starch, respectively). Conversely, the HMW fraction predominated in highly digestible starches. For instance, 65 and $58 \%$ of starch in LAMS custard and muesli, respectively, was the HMW fraction (see Table 2).

The MMW fraction accounted for between just 12 and $20 \%$ of the starch present in ileal effluent for the different food products that were consumed (Table 2) whereas the LMW fraction predominated at $45-68 \%$ of total starch. Muesli and LAMS custard contained proportionately less of the LMW and more of the HMW fractions than the RS in beans and HAMS custard.

The HMW starch fraction in muesli, bread, LAMS custard and fries was digested extensively (between 93 and 98\%) whereas that in beans (only $35 \%$ of HMW starch digested) and to a lesser extent HAMS custard (67\% digested) was not. The MMW starch fraction appeared to be highly susceptible to amylolysis in vivo regardless of the food product. For all test foods, $<10 \%$ of this fraction was present in ileal digesta relative to that in the food consumed. Although a recent study of starch digestion in vitro has shown that molecular reorganisation was likely to take place during the enzyme-digestion process ${ }^{(13)}$ (i.e. formation of recrystallised amylosic fragments during digestion), molecular reorganisation does not seem to happen during in vivo digestion (ZK Zhou, AR Bird, DL Topping and MK Morell, unpublished results). Thus, much more of the LMW starch fraction was assumed to be retained during the passage of starch through the upper gut. For instance, in the case of beans, more than $76 \%$ of the LMW fraction appeared to be resistant to amylolysis; however, it is possible that some of the MMW and LMW fractions were derived from incomplete digestion of higher-MW starches (see Discussion).

From a quantitative perspective, the LMW fraction accounts for the greatest yield of RS for all six foods. For instance, consumption of $100 \mathrm{~g}$ mixed beans would result in $3.3 \mathrm{~g}$ LMW starch reaching the terminal ileum compared with just 0.7 and $0.8 \mathrm{~g} \mathrm{MMW}$ and HMW fractions, respectively. Muesli was unusual in that this food yielded a comparatively substantial amount of HMW RS (1.6 g/100 g food).

Scanning electron micrographs of starch granules in the test foods and stomal effluent of volunteers after test food ingestion are shown in Fig. 2. Granules in all foods had an irregular shape, with the size distribution ranging from 8 to $40 \mu \mathrm{m}$, and surface cracks clearly evident, whereas the morphology of starch in ileal digesta (Fig. 2) was markedly different. The granules were generally smaller, the size distribution being between 2 and $7 \mu \mathrm{m}$ according to the objective observations, and the surface relatively smooth compared with granules present in the foods.

FTIR spectral absorbances at 1047 and 1022 per $\mathrm{cm}$ were measured for starches in each food and in corresponding 
Table 2. Molecular profile of starch in food and ileal digesta (Mean values with their standard errors*)

\begin{tabular}{|c|c|c|c|c|c|c|c|c|c|c|c|c|}
\hline \multirow[b]{4}{*}{ Test food } & \multicolumn{12}{|c|}{ Proportion of each molecular fraction (\%)† } \\
\hline & \multicolumn{6}{|c|}{ Food } & \multicolumn{6}{|c|}{ Ileal digesta } \\
\hline & \multicolumn{2}{|c|}{ HMW } & \multicolumn{2}{|c|}{ MMW } & \multicolumn{2}{|c|}{ LMW } & \multicolumn{2}{|c|}{ HMW } & \multicolumn{2}{|c|}{ MMW } & \multicolumn{2}{|c|}{ LMW } \\
\hline & Mean & SEM & Mean & SEM & Mean & SEM & Mean & SEM & Mean & SEM & Mean & SEM \\
\hline Muesli & 58.4 & 0.4 & $25 \cdot 4$ & 0.6 & $16 \cdot 2$ & 0.2 & 37.9 & 0.7 & $12 \cdot 9$ & 0.5 & $49 \cdot 2$ & 0.9 \\
\hline Bread & 33.9 & 1.7 & $36 \cdot 1$ & 0.7 & $30 \cdot 0$ & $2 \cdot 3$ & $24 \cdot 2$ & $2 \cdot 0$ & $19 \cdot 9$ & $1 \cdot 1$ & 55.9 & 1.7 \\
\hline Fries & 19.9 & 0.9 & 50.9 & 0.8 & $29 \cdot 2$ & 0.0 & $28 \cdot 2$ & 2.5 & 11.9 & 0.7 & $59 \cdot 9$ & $2 \cdot 7$ \\
\hline Beans & $9 \cdot 8$ & 0.2 & $58 \cdot 2$ & 1.0 & $32 \cdot 1$ & 0.7 & 17.5 & 1.8 & $14 \cdot 8$ & 0.4 & $67 \cdot 8$ & 1.6 \\
\hline Custard, LAMS & $65 \cdot 3$ & 1.6 & 29.5 & 0.3 & $5 \cdot 2$ & 1.9 & 36.9 & $4 \cdot 1$ & $18 \cdot 1$ & 0.6 & $45 \cdot 3$ & $4 \cdot 1$ \\
\hline Custard, HAMS & $16 \cdot 0$ & 0.2 & $45 \cdot 1$ & 5.5 & 38.9 & 5.7 & $18 \cdot 3$ & $1 \cdot 1$ & $14 \cdot 6$ & 0.5 & $67 \cdot 1$ & 1.3 \\
\hline
\end{tabular}

\begin{tabular}{|c|c|c|c|c|c|c|c|c|c|c|c|c|c|c|c|}
\hline \multirow[b]{4}{*}{ Test food } & \multicolumn{12}{|c|}{ Amount of each molecular fraction $(\mathrm{g} / 100 \mathrm{~g}$ food $) \ddagger$} & & & \\
\hline & \multicolumn{6}{|c|}{ Food } & \multicolumn{6}{|c|}{ Ileal digesta } & & & \\
\hline & \multicolumn{2}{|c|}{ HMW } & \multicolumn{2}{|c|}{ MMW } & \multicolumn{2}{|c|}{ LMW } & \multicolumn{2}{|c|}{ HMW } & \multicolumn{2}{|c|}{ MMW } & \multicolumn{2}{|c|}{ LMW } & \multicolumn{3}{|c|}{$\begin{array}{l}\text { Digestibility of each } \\
\text { molecular fraction (\%)§ }\end{array}$} \\
\hline & Mean & SEM & Mean & SEM & Mean & SEM & Mean & SEM & Mean & SEM & Mean & SEM & HMW & MMW & LMW \\
\hline Muesli & $26 \cdot 86$ & 0.17 & 11.68 & 0.26 & 7.45 & 0.01 & 1.55 & 0.03 & 0.53 & 0.02 & 2.02 & 0.04 & 94.2 & 95.5 & $72 \cdot 9$ \\
\hline Bread & 17.49 & 0.87 & $18 \cdot 62$ & 0.34 & $15 \cdot 48$ & 1.20 & 0.60 & 0.05 & 0.50 & 0.03 & 1.40 & 0.04 & $96 \cdot 6$ & $97 \cdot 3$ & 90.9 \\
\hline Fries & $5 \cdot 87$ & 0.25 & $15 \cdot 03$ & 0.24 & 8.62 & 0.01 & 0.40 & 0.03 & 0.17 & 0.01 & 0.84 & 0.03 & $93 \cdot 2$ & 98.9 & $90 \cdot 2$ \\
\hline Beans & $1 \cdot 30$ & 0.87 & $7 \cdot 71$ & 0.34 & 4.25 & 1.20 & 0.84 & 0.09 & 0.71 & 0.02 & 3.25 & 0.08 & $35 \cdot 4$ & $90 \cdot 8$ & 23.5 \\
\hline Custard, LAMS & $9 \cdot 21$ & 0.23 & $4 \cdot 16$ & 0.04 & 0.73 & 0.27 & 0.21 & 0.02 & $0 \cdot 10$ & 0.01 & 0.26 & 0.02 & $97 \cdot 7$ & 97.5 & $64 \cdot 6$ \\
\hline Custard, HAMS & 2.39 & 0.04 & $6 \cdot 72$ & 0.81 & 5.80 & 0.86 & 0.79 & 0.05 & 0.63 & 0.02 & 2.90 & 0.05 & $66 \cdot 8$ & 90.6 & 49.9 \\
\hline
\end{tabular}

LMW, low molecular weight; MMW, medium molecular weight; HMW, high molecular weight; LAMS, low-amylose maize starch; HAMS, high-amylose maize starch.

*Values of duplicate determinations for food and ileal digesta samples from eight ileostomates (each ileal sample was analysed in duplicate).

† Proportion of each starch molecular fraction in food or digesta was calculated as the peak area relative to total peak area (aggregate of HMW, LMW and LMW).

$\ddagger$ Starch molecular profile presented as the quantity of each fraction contained in either $100 \mathrm{~g}$ of food or ileal digesta.

$\S$ Ileal digestibility of starch molecular fractions expressed as a proportion of starch consumed. 

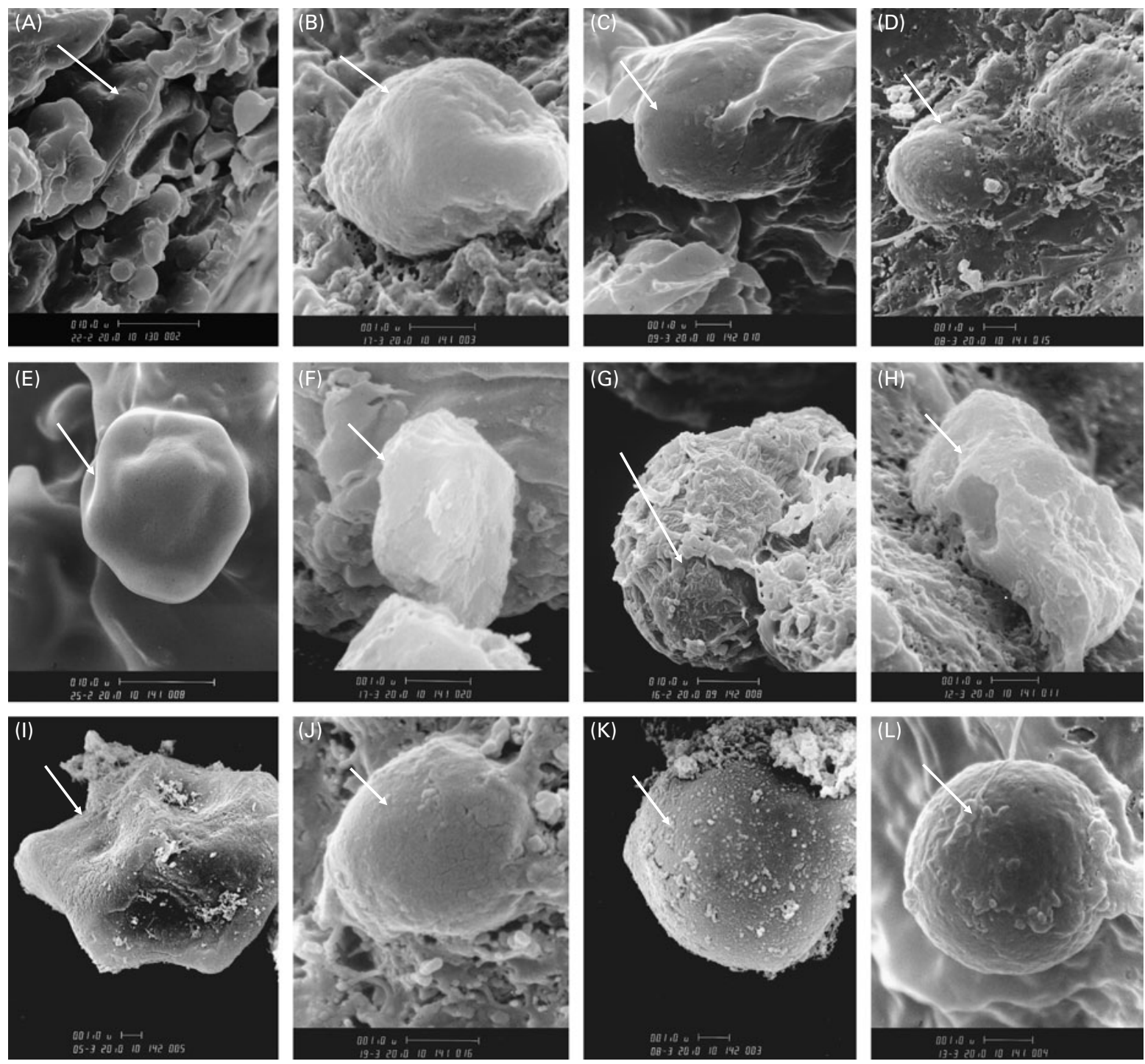

Fig. 2. Scanning electron micrographs of starches present in test foods and corresponding digesta. (A) and (B), muesli food and its digesta; (C) and (D), bread food and its digesta; $(E)$ and $(F)$, fries food and its digesta; $(G)$ and $(H)$, bean food and its digesta; $(\mathrm{I})$ and $(\mathrm{J})$, custard containing conventional maize starch and its digesta; $(K)$ and $(L)$, custard containing high-amylose maize starch and its digesta. $\rightarrow$, Starch particle. Scale bar $=1.0 \mu \mathrm{m}$.

digesta samples (for representative spectra, see Fig. 3). Absorptions at these wavelengths are thought to be suggestive of whether starch structures are more or less ordered ${ }^{(11,13,18)}$, respectively, and the ratio 1047:1022 per cm provides an indication of the relative structural organisation of the starches in these samples (Table 3) ${ }^{(11,13)}$. It is evident for bread (Fig. 3(A)) that the intensity of absorbance at 1022 per $\mathrm{cm}$ is much less in the digesta sample than in the food, whereas at 1047 per $\mathrm{cm}$ the converse was true. Consequently, the 1047:1022 per $\mathrm{cm}$ ratio was larger for starch resistant to digestion than for that in the food. A similar pattern was observed for the other foods and digesta samples (Table 3), indicating that the more ordered starch was less susceptible to amylolysis.

Iodine spectra for one food (bread) and a corresponding digesta sample are shown in Fig. 3(B). The wavelength for maximum absorption $\left(\lambda_{\max }\right)$ was greater for the starch in food compared with that remaining in ileal digesta and this pattern was common to the other products that were tested (Table 3).

\section{Discussion}

The aim of the present study was to determine the impact of human small-intestinal digestion on the physical attributes of starch in convenience foods. To our knowledge this is the first study of its kind. Previous studies in intact human subjects ${ }^{(19)}$, individuals with ileostomy ${ }^{(9)}$, intubated human subjects $^{(20)}$ or surgically modified animals ${ }^{(21)}$ have focused principally on the absolute amounts of RS in foods. Of the few studies that have investigated the structural properties of starch, the foods used have been either experimental or not commonly eaten or the study has been of limited scope $e^{(9,20,22-25)}$. The data we have gathered show that there were not only the expected substantial losses of starch in the small intestine but also changes in particle size distribution and internal order of the starches that escaped from the terminal ileum. The foods that we tested were chosen to provide a representative sample of convenience products consumed in Australia. The custards are not commercial products but 

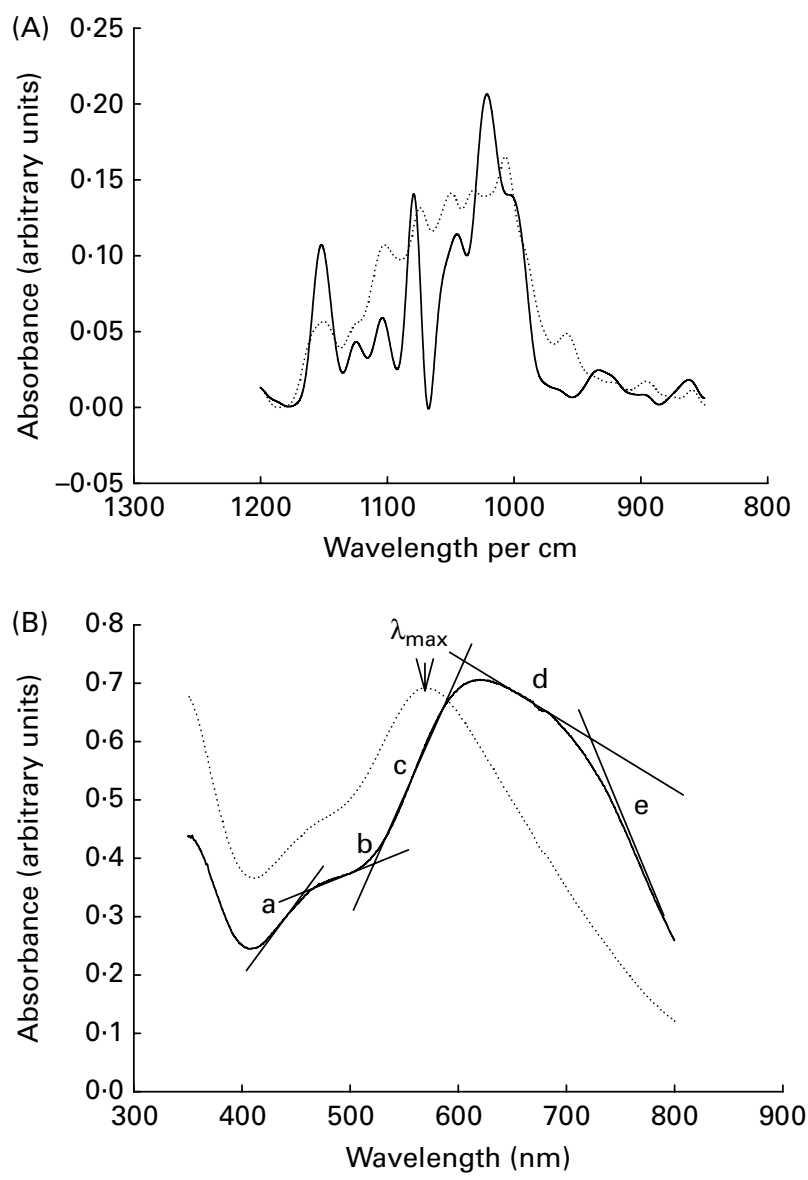

Fig. 3. Changes in the spectra before and after digestion, represented by bread $(-)$ and its corresponding digesta $(\cdots . .$.$) . (A) Fourier transform IR$ spectrum ranging from 1200 to 850 per $\mathrm{cm}$; (B) starch-iodine spectrum scanning from 800 to $350 \mathrm{~nm}$. Lines designated a and b represent the slopes of the left 'shoulder' region of the spectrum relating to complexation of iodine and shorter chains of amylose molecules; slopes $\mathrm{c}$ and $\mathrm{d}$ relate to complexation between iodine and longer chains of amylose molecules; e represents the slope of the right 'shoulder' region indicative of complexation between iodine and the longest amylase chains.

were examined because they contained maize starches of widely differing amylose content that have been the subject of extensive nutritional examination in human subjects ${ }^{(20,26)}$ and animals ${ }^{(27-29)}$.
Of the convenience foods examined, ileal starch digestibility was greatest for the cereal foods and chips and least for the beans. This accords with the view that legume starches are much less digestible than those in cereals ${ }^{(30-32)}$. This is borne out also by animal and human studies that show relatively high large-bowel SCFA production following legume consumption ${ }^{(33,34)}$. The high digestibility of the LAMS in custard and the much lower digestibility of HAMS were expected from animal and human studies ${ }^{(20,21,26,29,35)}$. This is consistent with the view that starch amylose content seems to play an important role in determining the RS content of foods ${ }^{(4,36)}$.

Before digestion, the starch granules had an irregular appearance with cracked and rough surfaces. In contrast, starches recovered from the ileal effluent were smaller and smoother. Previous human, animal and in vitro studies have shown similar changes that reflect the progressive erosion of granules by amylase ${ }^{(37)}$. As expected, there was a marked reduction in granule size from $8-40 \mu \mathrm{m}$ before digestion to about $7 \mu \mathrm{m}$ in the digesta. The relative contributions of the three major starch fractions were separated on the basis of MW using SE-HPLC. The largest of these was composed principally of amylopectin, a highly branched polymer. The medium fraction was mostly (but not exclusively) higherMW amylose while the smallest fraction was lower-MW amylose. Amylose is a smaller polymer than amylopectin with a less branched structure and amylose molecules have a high tendency to aggregate and crystallise during retrogradation compared with other starch fractions ${ }^{(38)}$. Consequently, this amylose-dominated structure would contribute to the formation of regions containing aggregates of aligned amylose chains following starch retrogradation ${ }^{(39)}$ within which there is a relatively high resistance to amylolysis. Although the individual test foods showed different starch MW distributions, all showed a consistent trend on digestion, i.e. a disproportionate loss of the MMW fractions and a relative enrichment of the LMW fractions in digesta. Between 91 and $99 \%$ of the MMW fractions of starch were lost on digestion, while there was retention of the LMW fraction, indicating that it is either resistant, or replenished from the products of breakdown of the MMW fraction during digestion. While the MMW fraction could be considered as amylose, it is clearly of a higher digestibility than the LMW fraction. The results from HPLC analysis support the previous suggestion ${ }^{(17,40)}$ that molecular

Table 3. Structural characteristics of starch in the six test foods and corresponding ileal digesta samples (Mean values with their standard errors)

\begin{tabular}{|c|c|c|c|c|c|c|c|c|}
\hline \multirow[b]{3}{*}{ Test food } & \multicolumn{4}{|c|}{ FTIR ratio $1047: 1022$ per cm } & \multicolumn{4}{|c|}{ Wavelength of $\lambda_{\max }(\mathrm{nm})$ for iodine spectra } \\
\hline & \multicolumn{2}{|c|}{ Food $^{*}$} & \multicolumn{2}{|c|}{ Digesta† } & \multicolumn{2}{|c|}{ Food $^{*}$} & \multicolumn{2}{|c|}{ Digesta† } \\
\hline & Mean & SEM & Mean & SEM & Mean & SEM & Mean & SEM \\
\hline Muesli & 0.67 & 0.02 & 1.05 & 0.03 & $618 \cdot 7$ & 0.3 & $559 \cdot 8$ & $1 \cdot 2$ \\
\hline Bread & 0.54 & 0.02 & 1.01 & 0.02 & $619 \cdot 3$ & 1.9 & 563.0 & 1.1 \\
\hline Fries & 0.66 & 0.02 & 1.09 & 0.03 & $617 \cdot 0$ & 1.0 & $568 \cdot 8$ & 1.0 \\
\hline Beans & 0.82 & 0.02 & 0.96 & 0.02 & $629 \cdot 3$ & $1 \cdot 2$ & $561 \cdot 4$ & 0.9 \\
\hline Custard, LAMS & 0.59 & 0.01 & 0.94 & 0.02 & 618.5 & 0.5 & $563 \cdot 1$ & 0.9 \\
\hline Custard, HAMS & 0.76 & 0.01 & 0.98 & 0.02 & 609.0 & 0.6 & 572.8 & 1.8 \\
\hline
\end{tabular}

FTIR, Fourier transform IR spectroscopy; LAMS, low-amylose maize starch; HAMS, high-amylose maize starch.

* Values of triplicate determinations for each food.

† Values of eight ileostomates for each test food (each sample measured in triplicate). 
size, rather than amylose content alone, is an important determinant of starch digestibility and, hence, RS. The small contribution of the HMW fraction to RS might be due to the reassociation of shorter double-helices of amylopectin branches formed during the retrogradation process ${ }^{(41,42)}$ or starch which is physically inaccessible to digestive enzymes as a consequence of the presence of plant cell walls (i.e. $\mathrm{RS} 1)^{(43)}$ or resistant granular architecture.

Both the FTIR data and the iodine spectra support the above suggestions. Absorptions at 1047 and 1022 per $\mathrm{cm}$ are indicative of more and less organised starch structures, respectively ${ }^{(11-13)}$. Using the absorbance ratio 1047:1022 per $\mathrm{cm}$, the FTIR results are consistent with a previous study ${ }^{(13)}$ showing that starch in the ileal effluent was more ordered than in the food. This differential spectrum indicates that less organised starch was much more sensitive to digestion, contributing less to RS than the more ordered fraction. However, the limitations of using FTIR spectroscopy to quantify starch molecular order must be acknowledged $^{(13)}$. Unlike NMR and X-ray diffraction, FTIR data provide an indirect measure of molecular order in starches. Nevertheless, the iodine spectra for the food and its corresponding digesta sample are consistent with the FTIR data. The lower absorption maximum wavelength $\left(\lambda_{\max }\right)$ of starch in digesta compared with that of the starch in the food indicates that the MW of the major amylose component of starch present in ileal digesta was smaller than that of amylose in the starch of the food. The narrower peak width of amylose in the HPLC chromatogram also indicates that digestion altered the amylose compositions before and after digestion.

To our knowledge, this is the first study to examine the effects of passage through the human small intestine on the structure of starch in commonly consumed foods. Previous reports, using microscopic visualisation, showed that digestion had altered the physical appearance of the granules. The present data show that there were also substantial changes in size distribution and an enrichment of RS in smaller, more ordered granules, higher in amylose. New cereal cultivars, high in amylose, are being developed to produce foods that improve human health ${ }^{(44,45)}$.

\section{Acknowledgements}

We thank Dr Julie Clarke for providing some of the digesta samples and for helpful discussion, Debbie Davies, Caroline Cooke, Julie Dallimore and Ben Scherer for their assistance with the conduct of the ileostomy studies and with food preparation, sample collection and pre-processing of ileal digesta, and Sylvia Usher for analysis of starch in food and digesta samples. The authors are indebted to the ileostomates who participated in the studies referred to in this paper.

The present study was supported by Food Futures National Research Flagship (Australia).

All authors contributed to designing the experiment, interpreting the data and preparing, revising and approving the final version of the manuscript. Z. Z. also processed and analysed the samples, and collated and summarised the data.

None of the authors has any conflict of interest.

\section{References}

1. Brand-Miller J, Hayne S, Petocz P, et al. (2003) Low-glycemic index diets in the management of diabetes: a meta-analysis of randomized controlled trials. Diabetes Care 26, 2261-2267.

2. Asp NG, Van Amelsvoort JMM \& Hautvast JGJ (1996) Nutritional implications of resistant starch. Nutr Res Rev 9, $1-31$.

3. Topping DL \& Clifton PM (2001) Short-chain fatty acids and human colonic function: roles of resistant starch and nonstarch polysaccharides. Physiol Rev 81, 1031-1064.

4. Brown IL, McNaught KJ \& Moloney E (1995) Hi-maize ${ }^{\mathrm{TM}}$ : new directions in starch technology and nutrition. Food Aust 47, $272-275$.

5. Edwards CA \& Rowland IR (1992) Bacterial fermentation in the colon and its measurement. In Dietary Fibre. A Component of Food, pp. 119-136 [TF Schweizer and CA Edwards, editors]. London: Springer Verlag.

6. Nordgaard I, Mortensen PB \& Langkilde AM (1995) Small intestinal malabsorption and colonic fermentation of resistant starch and resistant peptides to short-chain fatty acids. Nutrition 11, 129-137.

7. Weaver GA, Krause JA, Miller TL, et al. (1992) Cornstarch fermentation by the colonic microbial community yields more butyrate than does cabbage fiber fermentation; cornstarch fermentation rates correlate negatively with methanogenesis. Am J Clin Nutr 55, 70-77.

8. Cummings JH, Beatty ER, Kingman SM, et al. (1996) Digestion and physiological properties of resistant starch in the human large bowel. Br J Nutr 75, 733-747.

9. Langkilde AM, Champ M \& Andersson H (2002) Effects of high-resistant-starch banana flour $(\operatorname{RS}(2))$ on in vitro fermentation and the small-bowel excretion of energy, nutrients, and sterols: an ileostomy study. Am J Clin Nutr $\mathbf{7 5}$, 104-111.

10. Clarke JM, Bird AR, Topping DL, et al. (2007) Excretion of starch and esterified short-chain fatty acids by ileostomy subjects after the ingestion of acylated starches. Am J Clin Nutr 86, 1146-1151.

11. Van Soest JJG, Tournois H, deWit D, et al. (1995) Short-range structure in (partially) crystalline potato starch determined with attenuated total reflectance Fourier-transform IR spectroscopy. Carbohydr Res 279, 201-214.

12. Sevenous O, Hill SE, Farhat IA, et al. (2002) Organisation of the external region of the starch granules as determined by infrared spectroscopy. Int J Biol Macromol 31, 79-85.

13. Htoon A, Shrestha AK, Flanagan BM, et al. (2009) Effects of processing high amylose maize starches under controlled conditions on structural organisation and amylose digestibility. Carbohydr Polym 75, 236-245.

14. Hoover R (2001) Composition, molecular structure, and physicochemical properties of tuber and root starches: a review. Carbohydr Polym 45, 253-267.

15. Tester RF, Karkalas J \& Qi X (2004) Starch-composition, fine structure and architecture. J Cereal Sci 39, 151-165.

16. Shi YC, Capitani T, Trzasko P, et al. (1998) Molecular structure of a low-amylopectin starch and other high-amylose maize starches. J Cereal Sci 27, 289-299.

17. Cairns P, Morris VJ, Botham RL, et al. (1996) Physicochemical studies on resistant starch in vitro and in vivo. J Cereal Sci $\mathbf{2 3}$, 265-275.

18. Liu Q, Charlet G, Yelle S, et al. (2002) Phase transition in potato starch-water system I. Starch gelatinization at high moisture level. Food Res Int 35, 397-407.

19. Symonds EL, Kritas S, Omari TI, et al. (2004) A combined ${ }^{13} \mathrm{CO}_{2} / \mathrm{H}_{2}$ breath test can be used to assess starch digestion and fermentation in humans. J Nutr 134, 1193-1196. 
20. Champ MM, Molis C, Flourie B, et al. (1998) Small-intestinal digestion of partially resistant cornstarch in healthy subjects. Am J Clin Nutr 68, 705-710.

21. Morita T, Kasaoka S, Hase K, et al. (1999) Psyllium shifts the fermentation site of high-amylose cornstarch toward the distal colon and increases fecal butyrate concentration in rats. $J$ Nutr 129, 2081-2087.

22. Botham RL, Cairns P, Faulks RM, et al. (1997) Physicochemcial characterisation of barley carbohydrates resistant to digestion in a human ileostomate. Cereal Chem 74, 29-33.

23. Faisant N, Champ M, Colonna P, et al. (1993) Structural features of resistant starch at the end of the human small intestine. Eur J Clin Nutr 47, 285-296.

24. Faisant N, Buleon A, Colonna P, et al. (1995) Digestion of raw banana starch in the small intestine of healthy humans: structural features of resistant starch. Br J Nutr 73, 111-123.

25. Faisant N, Gallant DJ, Bouchet B, et al. (1995) Banana starch breakdown in the human small intestine studied by electron microscopy. Eur J Clin Nutr 49, 98-104.

26. Noakes M, Clifton PM, Nestel PJ, et al. (1996) Effect of high-amylose starch and oat bran on metabolic variables and bowel function in subjects with hypertriglyceridemia. Am J Clin Nutr 64, 944-951.

27. Le Leu RK, Brown IL, Hu Y, et al. (2003) Effect of resistant starch on genotoxin-induced apoptosis, colonic epithelium, and lumenal contents in rats. Carcinogenesis 24, 1347-1352.

28. Brown IL (2004) Applications and uses of resistant starch. J AOAC Int 87, 727-732.

29. Bird AR, Vuaran M, Brown I, et al. (2007) Two high-amylose maize starches with different amounts of resistant starch vary in their effects on fermentation, tissue and digesta mass accretion, and bacterial populations in the large bowel of pigs. Br J Nutr 97, 134-144.

30. Schweizer TP, Anderson H, Langkilde AM, et al. (1990) Nutrients excreted in ileostomy effluents after consumption of mixed diets with beans or potatoes. II. Starch, dietary fibre and sugars. Eur J Clin Nutr 44, 567-575.

31. Noah L, Guillon F, Bouchet B, et al. (1998) Digestion of carbohydrate from white beans (Phaseolus vulgaris L.) in healthy humans. J Nutr 128, 977-985.

32. Rehman Zia-ur, Salariya AM \& Zafar SI (2001) Effect of processing on available carbohydrate content and starch digestibility of kidney beans (Phaseolus vulgaris L.). Food Chem 73, 351-355.

33. Fleming SE, Fitch MD \& Chansler MW (1989) High-fiber diets: influence on characteristics of cecal digesta including shortchain fatty acid concentrations and $\mathrm{pH}$. Am J Clin Nutr 50, 93-99.

34. Topping DL, Illman RJ, Clarke JM, et al. (1993) Dietary fat and fiber alter large bowel and portal venous volatile fatty acids and plasma cholesterol but not biliary steroids in pigs. J Nutr $\mathbf{1 2 3}$, $133-143$.

35. Morita T, Kasaoka S, Ohhashi A, et al. (1998) Resistant proteins alter cecal short-chain fatty acid profiles in rats fed high amylose cornstarch. J Nutr 128, 1156-1164.

36. Berry CS (1986) Resistant starch: formation and measurement of starch that survives exhaustive digestion with amylolytic enzymes during the determination of dietary fibre. $J$ Cereal Sci 4, 301-314.

37. Bird AR, Brown IL \& Topping DL (2000) Starches, resistant starches, the gut microflora and human health. Curr Issues Intest Microbiol 1, 25-37.

38. Parker R \& Ring SG (2001) Aspects of the physical chemistry of starch. J Cereal Sci 34, 1-17.

39. Shamai K, Bianco-Peled H \& Shimoni E (2003) Polymorphism of resistant starch type III. Carbohydr Polym 54, 363-369.

40. Eerlingen RC \& Delcour JA (1995) Formation, analysis, structure and properties of type III enzyme resistant starch. J Cereal Sci 22, 129-138.

41. Goodfellow BJ \& Wilson RH (1990) A Fourier transform IR study of the gelation of amylose and amylopectin. Biopolymers 30, $1183-1189$.

42. Gudmundsson M \& Eliasson AC (1992) Comparison of thermal and viscoelastic properties of four waxy starches and the effect of added surfactant. Starch/Stärke 44, 379-385.

43. Englyst HN, Kingman SM \& Cummings JH (1992) Classification and measurement of nutritionally important starch fractions. Eur J Clin Nutr 46, Suppl. 2, S33-S50.

44. Topping DL, Morell MK, King RA, et al. (2003) Resistant starch and health - Himalya 292, a novel barley cultivar to deliver benefits to consumers. Starch/Stärke 55, 539-545.

45. Ahmed R, Bird AR, Li Z, et al. (2007) Bioengineering cereal carbohydrates to improve human health. Cereal Foods World 52, $182-187$. 